\title{
O IMPACTO PSICOLÓGICO DA VIOLÊNCIA E DO ABUSO NAS VIDAS DE CRIANÇAS DE RUA NO SRI LANKA
}

\author{
PSYCHOLOGICAL IMPACT OF VIOLENCE AND ABUSE IN THE \\ LIVES OF STREET CHILDREN IN SRI LANKA
}

Miriam Ittyerah B. D. Pathirana ${ }^{1}$

ITTYERAH, M.; PATHIRANA, B.D. O impacto psicológico da violência e do abuso nas vidas de crianças de rua no Sri Lanka. Rev. Bras. Cresc. Desenv. Hum., São Paulo, 10 (2), 2000.

Resumo: Crianças de rua do Sri Lanka, entre as idades de 5 e 11 anos, foram avaliadas psicologicamente quanto ao impacto da violência e de abuso, testando-se a quantidade de: agressão percebida; habilidades de enfrentamento; e impacto do abuso. Os resultados indicaram que as crianças mais novas manifestaram mais agressão do que as mais velhas e que os meninos eram mais agressivos do que as meninas. Esta agressão ocorreu principalmente ante a condição de abuso sexual. As crianças mais velhas pareceram ser capazes de um enfrentamento melhor do que as menores sendo que, as meninas, em geral, estavam mais capacitadas para o enfrentamento do que os meninos. O impacto psicológico do abuso pareceu ser mais grave quando sob as formas de depressão e de pensamentos suicidas. Muitas crianças sentiam que o abusado se tornaria um abusador ou um criminoso. Estes dados tem conseqüências de grande alcance em um país menos industrializado, como o Sri Lanka, embora esta influência seja principalmente um resultado da industrialização urbana.

Palavras-chave: crianças de rua: violência; abuso; Sri Lanka.

\section{INTRODUÇÃO}

A Convenção dos Direitos da Criança (adorada pelas Nações Unidas em 1989) define uma criança como qualquer pessoa abaixo de 18 anos de idade. Como um dos 71 signatários da convenção, o governo de Sri Lanka a reconhece. No entanto, nem todas as crianças têm uma infância feliz assim como nem todas as pessoas têm imagens similares de todas as crianças. Por exemplo: as crianças conhecidas como "crianças de rua" dificilmente podem ser pensadas como felizes. Tais crianças são, em geral, ou totalmente ignoradas ou consideradas socialmente como um aborrecimento. Outros ainda gostariam de salvá-las. Elas se parecem com figuras míticas, talvez por, romanticamente, parecerem estar livres das preocupações dos adultos, ou por parecerem especialmente imorais, ou por serem vítimas por demais patéticas. Porém, elas não são nem figuras forada lei nem "paisagem-sem-casa” a ser fotografadas como parte da sociedade urbana. São indivíduos com sonhos individuais, cada um diferente do outro, cada um com sua própria história, problemas, necessidades e esperanças.

Dentro da ampla categoria genérica criança de rua, encontram-se dois grupos distintos, delineados pelo grau de abandono que sofrem (UNICEF, 1990). São crianças na rua e crianças da rua As crianças na rua constituem, amplamente, a maior parte desta categoria. Este grupo consiste, basicamente, em crianças engajadas em co-

1 Department of Psychology, University of Delhi, Delhi - 1 10007, India.

Tradução: Elaine Pedreira Rabinovich 
mércio na rua, tal como engraxates, catadores de lixo e mensageiros. Estas crianças têm casa e devem voltar para as suas famílias ao final do dia. As crianças da rua escolheram a rua como casa e é na rua que procuram abrigo, sustento e amizades. Elas têm um contato ocasional com as suas famílias. Crianças abandonadas e destituídas são as mais vulneráveis. Tendo cortado todos os laços familiares, estão por si sós no enfrentamento de sua sobrevivência matérial e psicológica. Tanto a variável "família” quanto a variável "social” parecem ser determinantes importantes do problema.

Segundo vários estudos, os três determinantes interagentes do problema são: (a) industrialização rápida e crescimento urbano; (b) variáveis intra-familiares, tais como pais alcoolizados e drogados e o abuso emocional experimentado pela criança; (c) condições estressantes socioeconômicas no macro-sistema. Este último fator parece ser particularmente danoso nos países menos industrializados. De acordo com as estatísticas mundiais da Unicef de 1991, pelo menos metade da população rural está abaixo da linha de pobreza em cerca de um terço destes países. Além disto, o crescimento do produto interno bruto não se correlaciona com o crescimento do desenvolvimento social/humano (taxa de mortalidade infantil abaixo de 5 anos de idade). Isto sugere que as políticas gerais nacionais e suas prioridades são fatores contribuintes para o problema em questão.

Crianças de rua, particularmente as "na rua”, parecem ser frutos do processo gradual de abandono por suas famílias. A pobreza por si mesma não explica o processo; a estrutura da família e sua dinâmica parecem ser fatores fundamentais. Estes fatores refletem a capacidade de membros da família de permanecerem juntos frente a crises internas. Os países do Sul Asiático, como Índia, Sri Lanka e Bangladesh, por exemplo, possuem mais “famílias na rua” do que "crianças na rua”. Conflitos entre os pais parecem ser cruciais no começo ao processo de abandono da criança, e isto é agravado pelas variáveis sociais atuantes. A migração de famílias pobres fugindo de condições estressantes (ex: terrorismo em Sri Lanka, e seca na Índia) para as cidades industrializadas, a falta de oportunidades de emprego e habitação e suas conseqüentes concentrações em favelas urbanas, e novos estresses nos conflitos familiares, eventualmente expelem a criança. Pesquisas apontam para a escola como variável reforçadora devido à sua incapacidade de reter os alunos. Segundo estatísticas locais, em 1986, 63\% das crianças de rua de Colombo estavam entre 11 e 15 anos de idade, sendo que a maioria destas crianças estavam na faixa etária crítica escolarmente considerando, entre os 6 e 15 anos de idade.

Foram feitas algumas tentativas para educar estas crianças, alterar suas atitudes de dependência, mudar a atitude de dura indiferença da sociedade mais ampla e promover uma resposta humana para estas crianças infortunadas. Contudo, há uma necessidade urgente de um programa que possa substituir a casa/escola, ou ambas, de modo a terminar não com as crianças de rua mas, sim, com os seus problemas. Devido a que as atuais iniciativas, tanto governamentais quanto não governamentais, fracassam em ir ao encontro das necessidades destas crianças, as crianças de rua em Sri Lanka são testemunhas de violência quase todos os dias. A maioria das crianças, tanto da rua quanto na rua, sofreram alguma forma de abuso seja ele físico, emocional ou sexual.

Segundo GERBNER et al. (1979), a violência é a experiência evidente de força física com ou sem uma arma contra si ou contra o outro; uma ação obrigatória, contra a vontade de alguém, de ferir ou de matar, ou realmente ferindo ou matando. De acordo com este ponto de vista, os atos de agressão devem (1) ser dirigidos a um ser humano, (2) ferir ou matar ou ameaçar ferir ou matar, (3) ser, de modo claro, não ambíguo e declaradamente, uma violência física.

A violência sob a forma de abuso físico pode ser definida como qualquer criança que sofre lesões não acidentais (CATTANACH, 1993), tais como maus tratos, queimaduras, etc. e podem ocorrer na família, na escola ou na sociedade. Em estudo realizado em Bhuwaneswar (PANDA, 1994), de 353 crianças de rua entrevistadas, 15\% foram molestadas pela polícia, $42,5 \%$ por pessoas em geral, embora nenhuma delas tenha relatado ter sido molestada por seu empregador. O impacto do abuso físico é diversificado, tal como: morte $(11 \%)$; lesões permanentes (28\%) (KEMPE, SILVERMAN, STEELE, DROEGEMUELLER \& SILVER, 1962); anormalidades neurológicas (53\%) (MARTIN, BEEZLEY, CONWAY, \& KEMPE, 1974); e invalidez por dano visual.

$\mathrm{O}$ abuso emocional inclui atitudes negativas ativas ou verbais ou ainda ataques emocionais, e a maioria dos históricos de casos mostram instâncias de abuso emocional (ARIMPOOR, 1992; PANICKER \& NANGIA, 1992). O impacto do abuso emocional inclui um aumento dos níveis de ansiedade, de tristeza e de doenças psicossomáticas, e de baixos níveis de competência, principalmente nos meninos (JAFFE et al., 1985).

O abuso sexual é definido como o envolvimento de crianças e adolescentes, desenvol- 
vimentalmente imaturos e dependentes, em atividades sexuais que eles não compreendem realmente (SCHECHETER \& ROBERT, 1976) tais como comentários verbais ou toques. O impacto do abuso sexual tem um alcance muito maior na forma de vergonha e culpa a longo prazo.

As crianças de rua sofrem violência e abuso na maioria das vezes por estarem desprotegidas e socialmenteprivadas. Estudando o efeito e o impacto da violência e do abuso, sentimos que medidas pertinentes poderiam ser tomadas destinadas a implementar intervenções apropriadas. O modo mais popular de estudar esse tema tem sido através de questionários. Isto desenvolveu, em conseqüência, uma tendência a fabricar eventos e a esconder fatos da vida destas crianças. Então, pensou-se que testando a sua agressão, capacidades de enfrentamento e impacto do abuso, através de estórias interessantes a elas, a realidade da situação poderia ser melhor compreendida. Em decorrência, espera-se que os resultados do presente estudo venha a ajudar professores, orientadores e demais profissionais que estudam crianças de rua a compreender e identificar os problemas encarados por elas devido ao abuso que sofrem e da violência que testemunham.

\section{MÉTODO}

Os objetivos do estudo foram os seguintes: (1) determinar se testemunhar violência e experienciar abuso pode causar dificuldades psicológicos e sócio-emocionais em crianças de rua; (2) testar sua consciência quanto a estratégias de enfrentamento e saber se crianças mais velhas ou mais jovens diferem entre si quanto às estratégias de enfrentamento, quanto à agressão e quanto ao impacto psicológico da violência e do abuso. Foi hipotetizado que a quantidade de agressão e das estratégias de enfrentamento difeririam nos grupos por idade e sexo.

\section{Sujeitos}

Um total de 40 crianças de rua, que sofreram alguma forma de violểncia, tal como violência física, emocional ou sexual em qualquer época de suas vidas, foram escolhidas ao acaso em Sarvodaya, Sri Lanka. Todas as crianças eram ou crianças na rua ou da rua. As idades das crianças variaram de 5 a 14 anos, havendo 20 crianças entre 5 e 9 anos, compreendendo o grupo de crianças menores, e 20 outras dentro da faixa de 10 a 15 anos compreendendo o grupo mais velho. Havia tantos meninos quanto meninas em cada grupo etário.

\section{Materiais-estímulo}

Foram utilizados os seguintes materiais: (1) Estória de um menino de rua chamado Ramu, em três condições diferentes. (2) Dois conjuntos de escalas de avaliação pictórica de 5 pontos (uma retratando as várias ações de agressão de Ramu e a outra retratando suas capacidades de enfrentamento). (3) Cinco pranchas pictóricas retratando o impacto do abuso, (4) um gravador para gravar a narrativa das crianças.

Uma revisão da literatura relacionada ao tema providenciou urna base de dados e um guia para a construção dos instrumentos. Enquanto esses eram construídos, foram levadas em consideração sua relevância e significação para os sujeitos e a baixa duração de atenção dos mesmos. Tomou-se cuidado para eliminar os viéses presentes em testes padronizados, dado que as crianças de rua estão expostas a um ambiente diferenciado. As instruções e as estórias propostas pelos instrutores do projeto de crianças de rua de Sarvodaya foram úteis tanto ao fazer as observações necessárias durante a coleta de dados quanto na interpretação das narrativas. A discussão e a consulta a vários funcionários de ONGs também contribuiu para construir estes instrumentos.

\section{Estória de um menino de rua chamado Ramu}

Uma estória de um menino de rua chamado Ramu foi contada para os participantes. A estória consistia em três seções, que continham três formas de abuso, i.e., abuso físico, abuso emocional e abuso sexual.

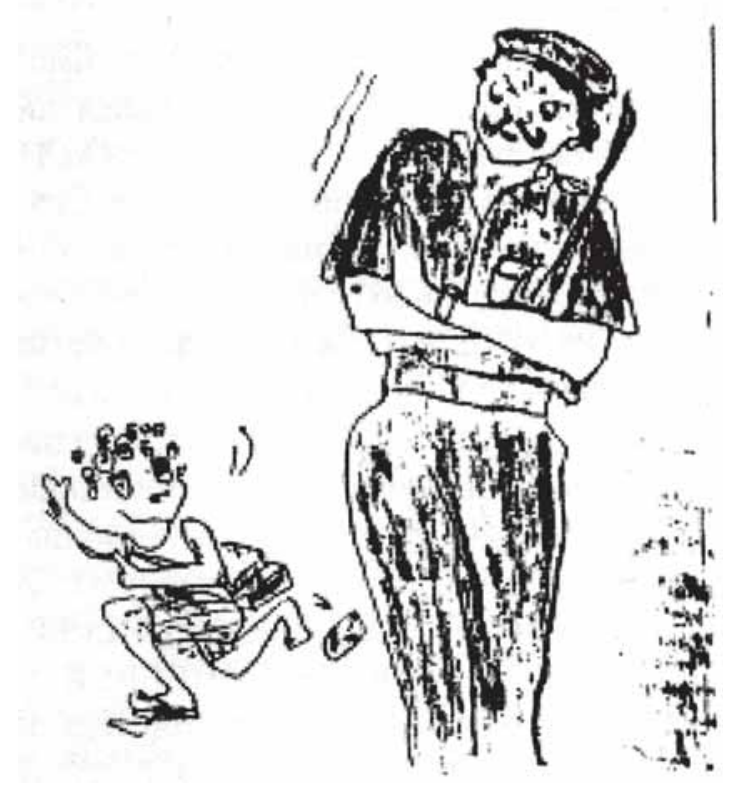

Figura 1-1: O abuso físico (o policial). 
A condição de abuso físico: a primeira seção revela Ramu sendo abusado por um policial. A estória é a seguinte: Este é Ramu (mostre a figura 1). Ramu é um pequeno menino de rua que não está morando com seus pais. Ele vende jornais e lixo para conseguir algum dinheiro. Este é o inspetor Silva (mostra a figura 1-l). Ele não gosta de pequenos meninos de rua que mendigam. Se ele vê meninos de rua mendigando, eles apanham muito. Um dia Ramu não podia encontrar comida, nem dinheiro para comprar comida. Daí ele começou a pedir dinheiro aos transeuntes. O Inspector Silva viu isto e surrou Ramu. Agora Ramu se sente muito triste e zangado porque se ele tivesse comida ou dinheiro, ele não teria mendigado, teria?

A condição de abuso emocional e maus tratos: O único parente de Ramu é o seu tio que é alcoólatra (mostra a figura 1-2). Ele não dá nada para Ramu comer e o repreende duramente. As vezes ele surrupia o duro dinheirinho ganho por Ramu para comprar bebida. Um dia o tio de Ramu pede a ele 5 reais. Quando Ramu recusa porque ele não tinha nenhum dinheiro, seu tio ralha com ele dizendo, "por causa de teu destino azarado teus pais morreram - você é o mais desgraçado e o teu destino é o mais miserável neste mundo ...etc.”. Naquele dia, Ramu se sentiu muito triste, e zangado com seu tio.

A condição de abuso sexual: Este é o Senhor Musculoso local (mostra a figura 1-3) Ele gosta de machucar crianças pequenas. Quando as crianças de rua estão dormindo, ele vem algumas vezes e toca-as em lugares que elas não querem.

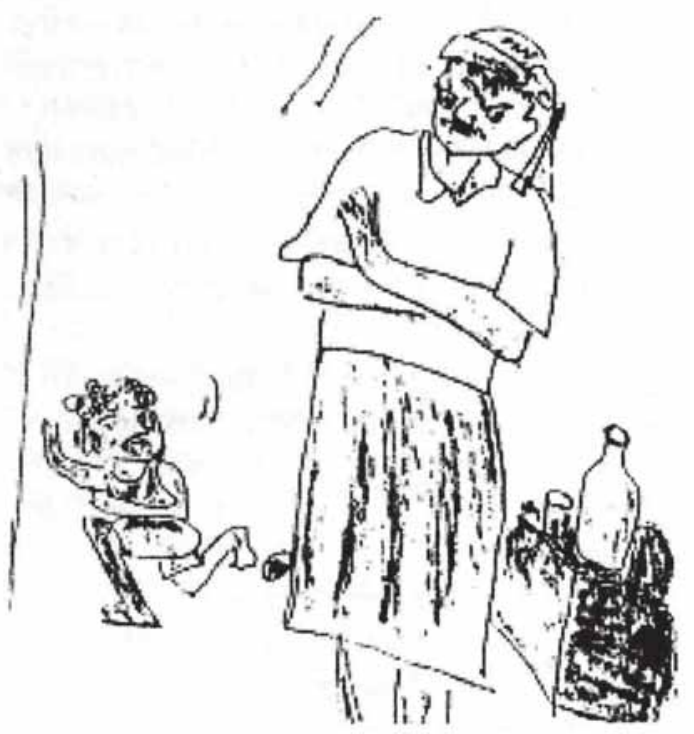

Figura 1-2: $\mathrm{O}$ abuso físico (o tio).

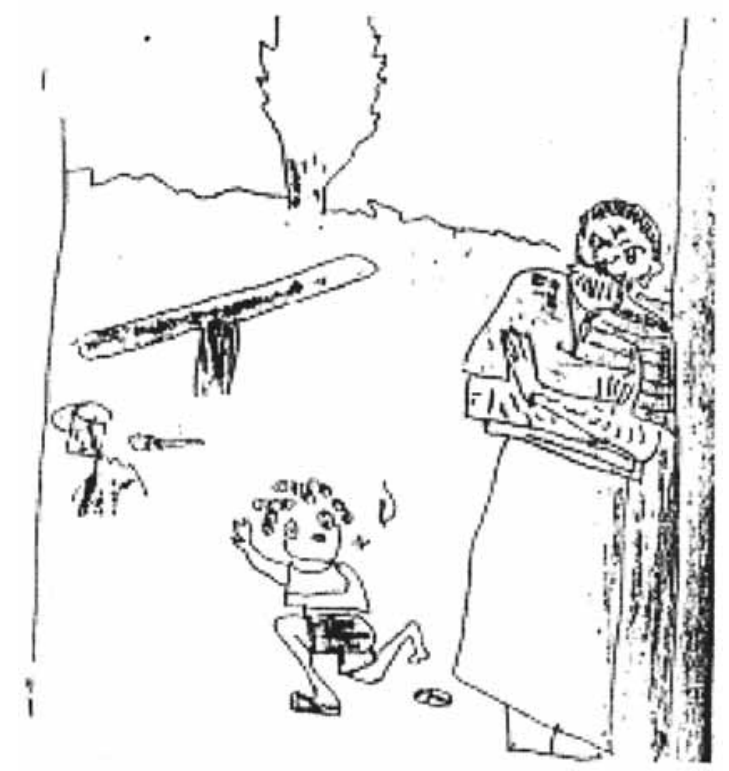

Figura 1-3: 0 abuso físico (o homem musculoso).

Rarnu é a sua presa mais fácil porque Ramu não tem ninguém que o protege. Ramu odeia o que o Sr. Musculoso faz com ele e se sente muito zangado com o Sr. Musculoso.

Após narrar cada seção para as crianças, três questões foram perguntadas a cada criança referentes a cada uma das condições. No total, nove perguntas foram colocadas para cada criança.

\section{Pergunta 1: Quantidade de agressão}

Quando as crianças estão zangadas, elas podem sentir vontade de fazer certas coisas como as mostradas nestas figuras (Mostre a escala pictórica de avaliação). Se você fosse Ramu, o que você sentiria vontade de fazer ao policial/tio/ homem músculo?

\section{Pergunta 2: Capacidades de enfrentamento}

Suponha que você fosse Ramu, o que você faria para impedir de sofrer o abuso feito pelo policial/tio/homem-músculo?

\section{Pergunta 3: Impacto do abuso}

Quando as crianças sofrem abuso como este, certas coisas podem acontecer a elas como visto nestas figuras (mostre figuras retratando o impacto do abuso). Segundo você, que tipo de coisa (impacto) vai acontecer a Ramu por causa deste abuso físico/emcional/sexual)?

\section{Escalas de avaliação}

Escalas de avaliação pictórica de cinco pontos foram usadas para medir a quantidade de agressão, seu enfrentamento e o impacto do abu- 
so. Cinco figuras retratando várias formas de atos agressivos foram espalhadas na frente da criança e pedia-se a ela/ele que escolhesse um quadro dentre os cinco que retratasse $\mathrm{o}$ ato mais desejado que ela/ele teria vontade de realizar em relação ao violentador, se ele/ela fosse Ramu. Por exemplo, a menor quantidade de agressão era denotada no primeiro quadro, tendo uma ilustração de Ramu chorando, enquanto amaior quantidade de agressão estava denotada no último quadro, que tinha uma ilustração de Ramu segurando uma arma. A escala de avaliação pictórica para a agressão retratava o seguinte:

\section{Quantidade de agressão}

1. A menor quantidade de agressão: Ramu chorará e esquecerá o incidente porque não há nada que ele possa fazer (figura 2-1).

2. Pequena quantidade de agressão: Ramu usará de violência verbal contra uma outra criança que é mais desprotegida do que ele e aliviará sua raiva deste modo (deslocamento) (figura 2-2).

3. Quantidade moderada de agressão: Ramu usará de violência física contra outra criança mais desprotegida do que ele e alivia sua raiva (figura2-3).

4. Agressão severa: Ramu terá o desejo de usar de violência fisica contra seu abusador (policial, tio, homem-músculo) e fará isto se tiver oportunidade (figura 2-4).

5. Agressão alta: Ramu sentirá o desejo de matar o abusador (policial, tio, homem músculo) e fará isso quando tiver uma oportunidade (figura 2-5).

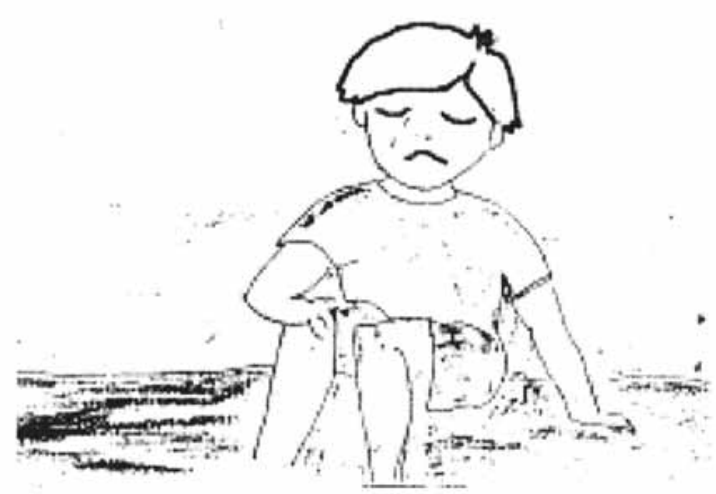

Figura 2-1: Agressão (choro).
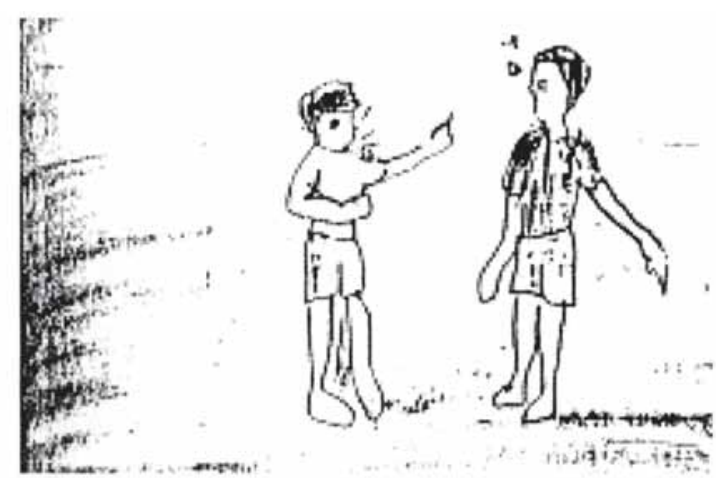

Figura 2-2: Agressão (abuso verbal).

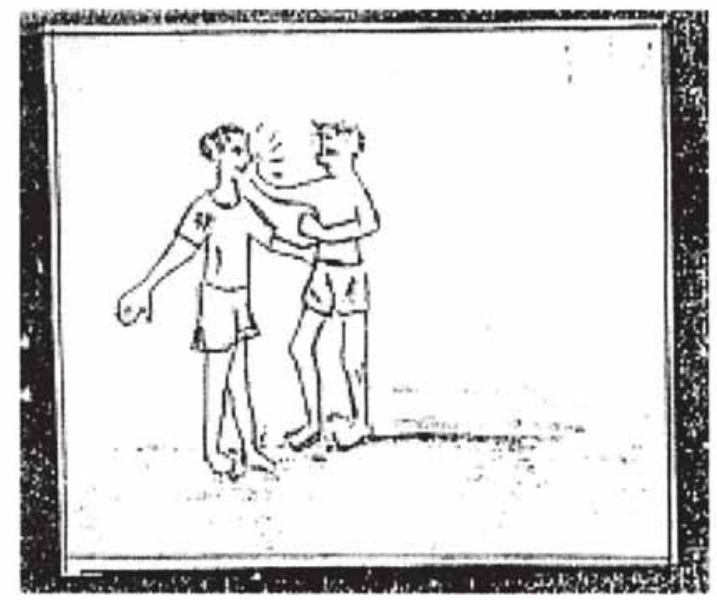

Figura 2-3: Agressão (abuso fisico).

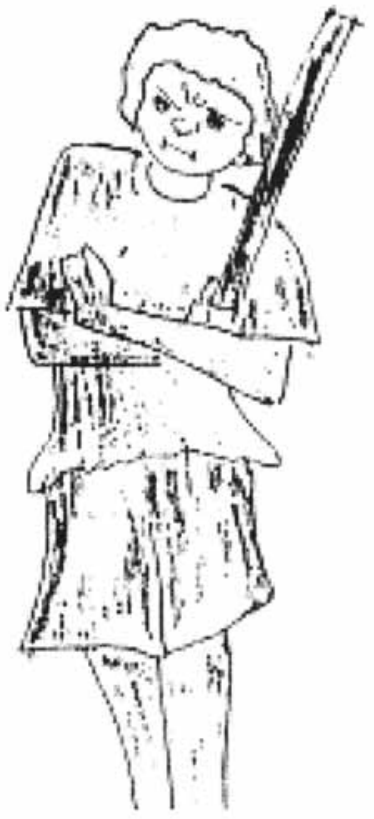

Figura 2-4: Agressão (agredir o agressor). 


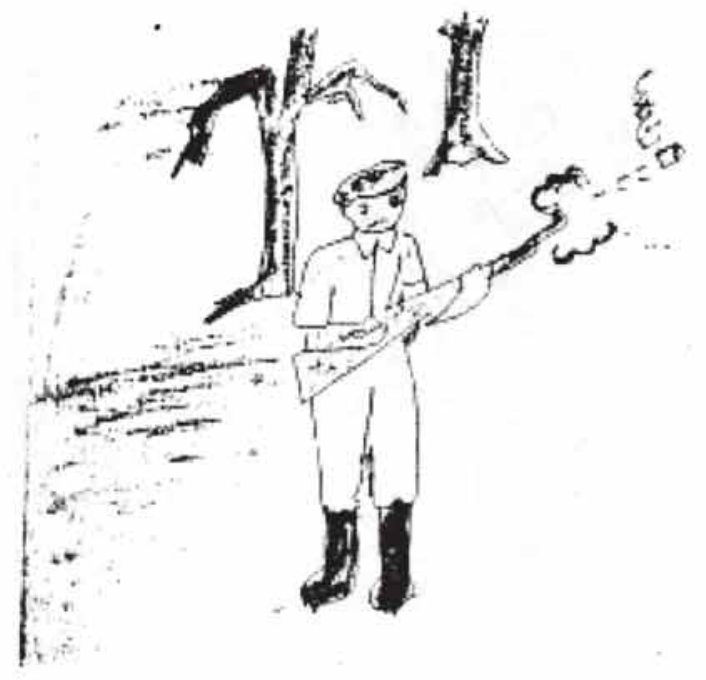

Figura 2-5: Agressão (matar o agressor)

\section{A força das estratégias de enfrentamento}

A escala de avaliação pictórica ilustrou as seguintes estratégias de enfrentamento:

1. Ramu chorará e nada fará para impedir de ser abusado no futuro (figura 3-1).

2. Ramu fugirá do abusador (policial/tio/ homem-músculo) (figura3-2).

3. Ramu apresentará uma queixa contra o policial (figura 3-3).

4. Ramu procurará ajuda de uma organização como Sarvodaya (figura 3-4).

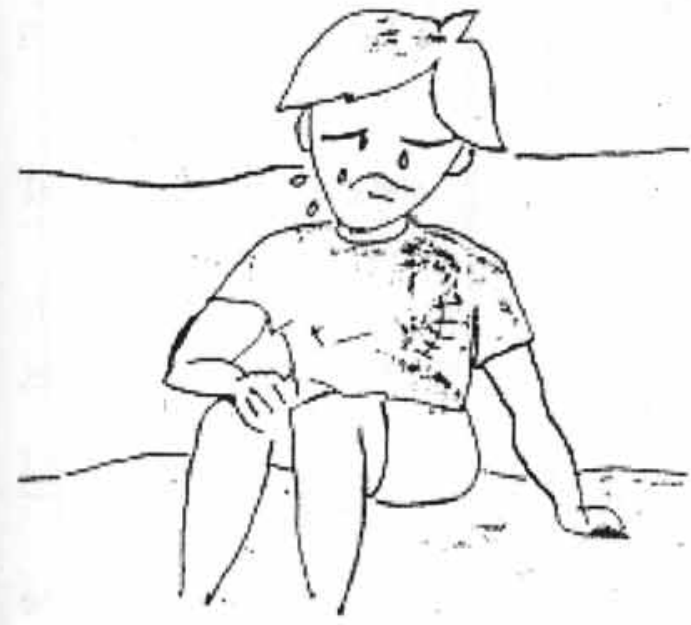

Figura 3-1: Enfrentamento (sentar e chorar)
5. Ramu participará de reuniões com outras crianças e protestará contra o abuso infantil (figura 3-5).

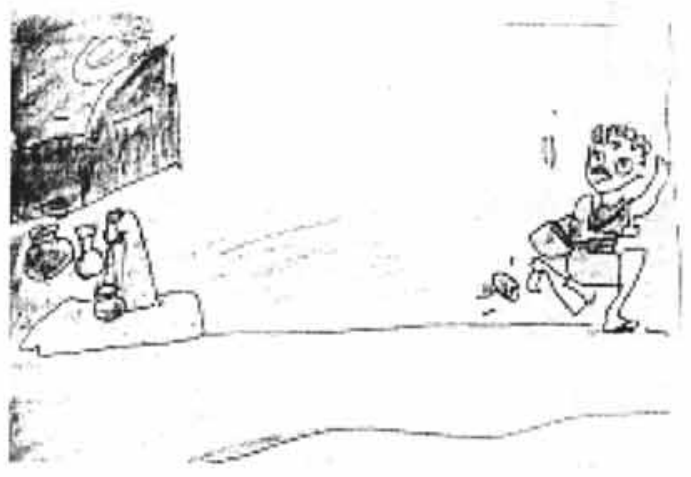

Figura 3-2: Enfrentamento (fuga)

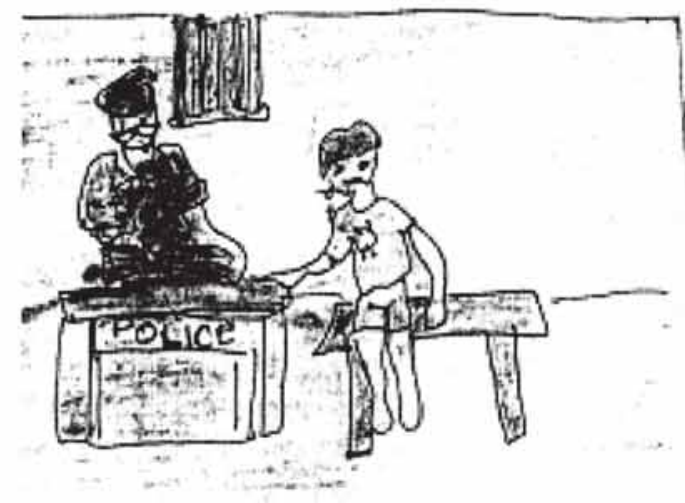

Figura 3-3: Enfrentamento (queixa à polícia)

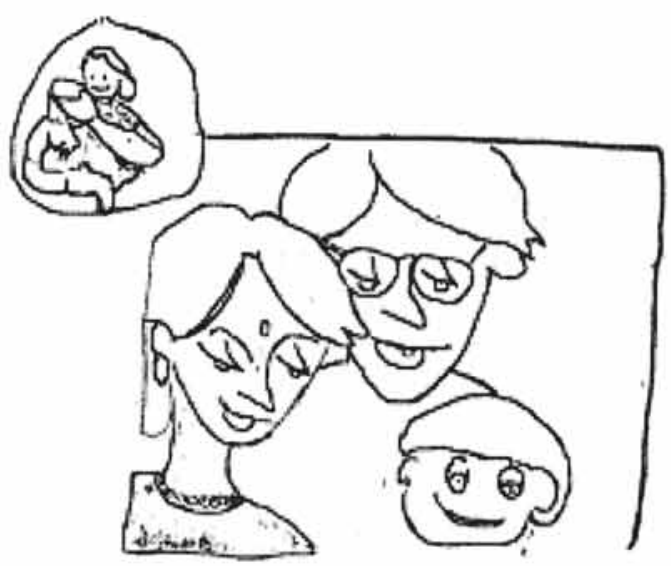

Figura 3 4: Enfrentamento (adoção) 


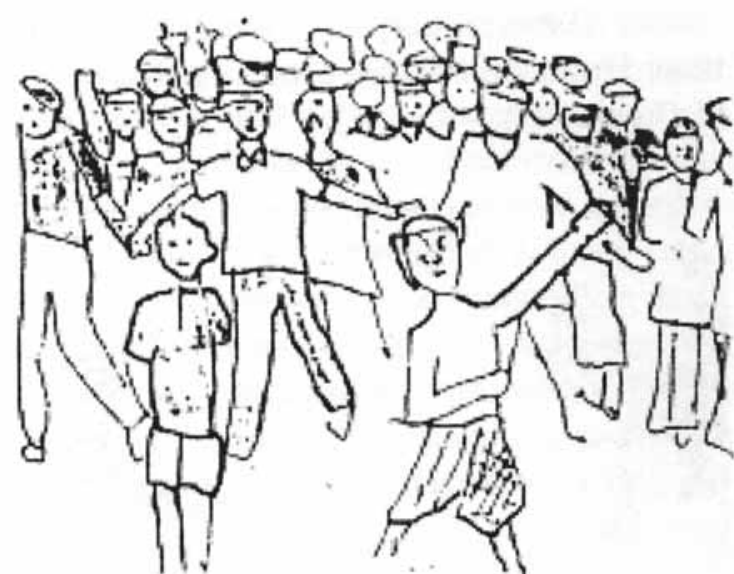

Figura 3-5: Enfrentamento (unir-se a outros)

\section{O impacto do abuso}

Uma vez mais, pediu-se à criança para escolher um quadro entre as cinco ilustrações que retratavam vários impactos psicológicos que podem afetar a criança de rua como resultado do abuso que elas experimentaram. Os impactos ilustrados são: (1) depressão (figura 4-1): (2) vício (figura 4-2); (3) incapacidadde de expressar emoções de alegria ou pesar (figura 4-3 e 4-4); (4) nunca ser capaz de confiar em adultos; (5) Ramu se tornar ele próprio um violentador, que irá mais tarde para a prisão em virtude dos abusos que ele pode infligir a outros (figura 4-5).

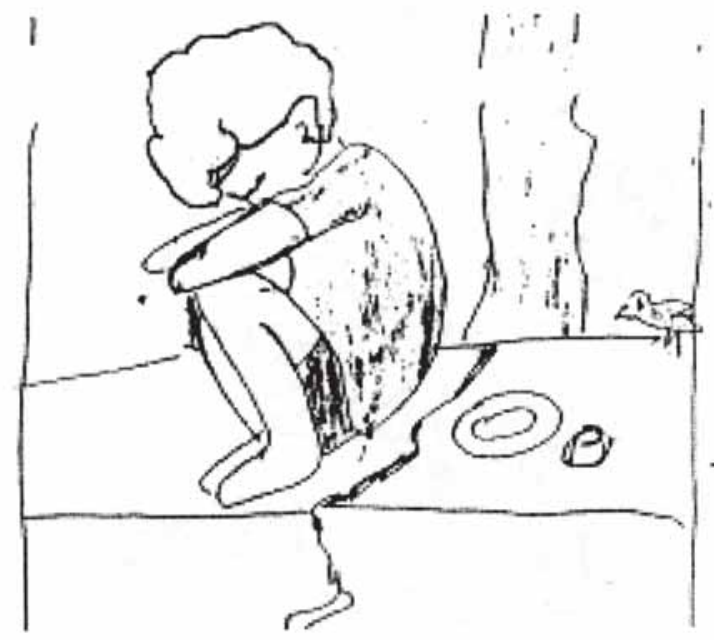

Figura 4-1: Impacto do abuso (depressão)

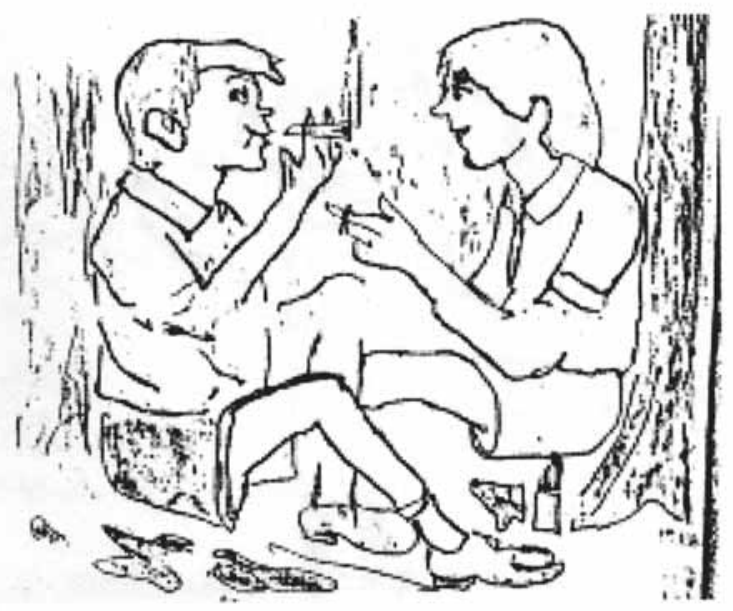

Figura 4-2: Impacto do abuso (uso de drogas)

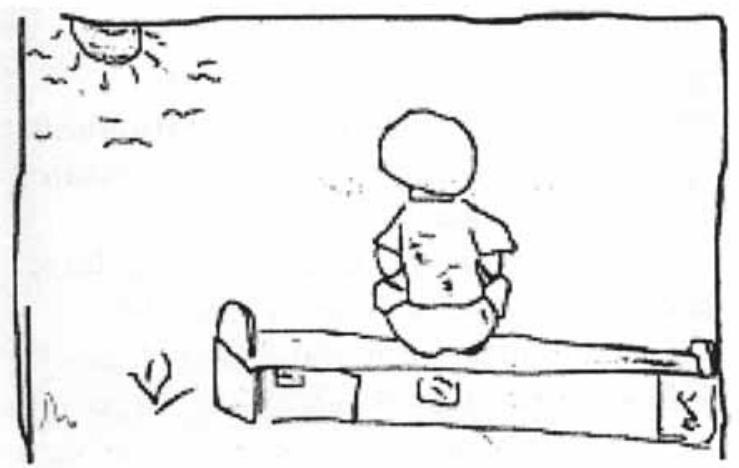

Figura 4-3 e 4-4: Impacto do abuso (isolamento)

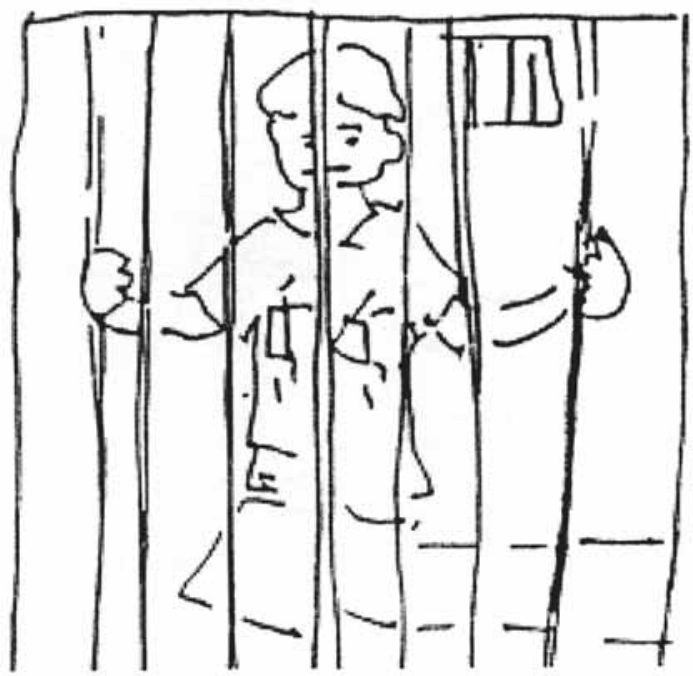

Figura 4-5: Impacto do abuso (o abusado se torna abusador) 


\section{NARRATIVAS}

RIESSMAN (1993) cunhou o termo "narratologia" em um esforço para elevar esta forma de análise a um status de objeto de conhecimento de uma nova ciência. A análise da narrativa toma como seu objeto de investigação a própria estória. O propósito da análise da narrativa é conhecer como os respondentes, em uma entrevista, impõem ordem ao fluxo das experiências para dar sentido aos eventos e ações em suas vidas. A abordagem metodológica examina a estória do informante e analisa como ela é organizada, as fontes lingüísticas e culturais em que se baseia e o modo pelo qual ela persuade o leitor de sua autenticidade. A análise em estudos de narrativas abrem-se às formas de contar sobre a experiência, e não simplesmente para o conteúdo ao qual a linguagem se refere. Porque a estória foi contada daquele modo? Portanto, segundo o analista da narrativa, a natureza e o mundo não contam estórias, são os indivíduos que o fazem. A interpretação é inevitável porque as narrativas são representações.

Por isso, pediu-se às crianças para criarem uma estória inventada por elas sobre uma criança de rua que experimentou abuso e testemunhou violência. Esperava-se que estas suas estórias contassem mais ainda sobre agressão, capacidades de enfrentamento e sobre o impacto do abuso.

\section{PROCEDIMENTO}

Contou-se a cada criança a estória das condições de abuso fisico, emocional e sexual e foi pedido que classificassem cada abuso pela quantidade de agressão percebida, após cada estória. Após isto, pediu-se que indicassem as estratégias de enfrentamento em relação ao abuso proposto. Isto foi seguido pela sua classificação do impacto do abuso. Finalmente, pediu-se a cada criança que contasse uma estória inventada por ela mesma sobre uma criança de rua semelhante a Ramu.

\section{RESULTADOS}

Os resultados do estudo foram analisados separadamente para agressão e para cada abuso. Finalmente, as narrativas das crianças repetiram a sua cognição do abuso, o seu impacto sobre elas e as suas conseqüências.

As médias e D.P. das crianças mais jovens e mais velhas mostraram que as crianças mais jovens eram mais agressivas c 0 que as crianças mais velhas, e mais para o abuso sexual do que para o físico e o emocional. Além disto, os meninos foram mais agressivos do que as meninas para os três tipos de abuso. Estes resultados estão apresentados na Tabela 1.

As avaliações das crianças para a quantidade de agressão percebida nos três abusos foram sujeitos ao ANOVA 2 (idade) x 2 (gênero) x 3 (abuso) com medidas repetidas do último fator (BROOTA, 1989). O ANOVA indicou que as crianças mais jovens eram mais agressivas $(F(1,36)=$ 4,74; $p<0,05$ ), embora não houvessem diferenças por gênero nem diferenças nos tipos de abuso. Somente a interação gênero $X$ abuso foi significativa $(\mathrm{F}(1,72)=6,99 ; \mathrm{p}<0,05)$. Os testes post hoc de Newman Keul (in WINER, 1971) indicaram mais agressão entre meninos $(F(1,72)=8,14 ; \mathrm{p}<0,01)$ para a natureza do abuso. Além disso, o abuso fisico $(\mathrm{F}(1,72)=10,53 ; \mathrm{p}<0,01)$ e o abuso sexual $(\mathrm{F}(1$ $, 72)=4,9 ; \mathrm{p}<0,01$ ) foram mais agressivamente percebidos do que o abuso emocional por meninos e meninas.

\section{Enfrentamento}

As médias e DP das avaliações para o enfrentamento do abuso indicaram que as crianças mais velhas possuíam melhores estratégias de enfrentamento do que as crianças mais jovens. Além

Tabela 1a: Resultado médio quanto à quantidade de agressão.

\begin{tabular}{lcccccc}
\hline & \multicolumn{2}{c}{ Física } & \multicolumn{2}{c}{ Emocional } & \multicolumn{2}{c}{ Sexual } \\
& meninos & meninas & meninos & meninas & meninos & meninas \\
\hline Crianças mais jovens (5- 9 anos) & 8.4 & 5.2 & 6.6 & 6.4 & 9.1 & 7.1 \\
Crianças mais velhas (10 -14 anos) & 7.6 & 4.4 & 5.2 & 6.2 & 8.0 & 5.6 \\
\hline
\end{tabular}

Tabela 1b: Desvio padrão para a quantidade de enfrentamento.

\begin{tabular}{lcccccc}
\hline & \multicolumn{2}{c}{ Física } & \multicolumn{2}{c}{ Emocional } & \multicolumn{2}{c}{ Sexual } \\
& meninos & meninas & meninos & meninas & meninos & meninas \\
\hline Crianças mais jovens (5-9 anos) & 15.82 & 5.56 & 5.85 & 7.10 & 14.47 & 9.37 \\
Crianças mais velhas (10 -14 anos) & 7.60 & 4.40 & 5.20 & 6.20 & 8.00 & 5.60 \\
\hline
\end{tabular}


disto, as meninas pareceram ser capazes de enfrentar melhor do que os meninos em todos os três abusos. A Tabela 2 mostra estes efeitos.

As avaliações das crianças para o enfrentamento foram submetidas a um ANOVA de 2 (idade) x 2 (gênero) x 3 (abuso) com medidas repetidas do último fator. Os resultados indicaram que o efeito da idade é significativo $(F(1,36)=4,92$; $\mathrm{p}<0,01)$ mostrando que as crianças mais velhas foram capazes de um melhor enfrentamento do que as crianças mais jovens $\mathrm{O}$ único outro efeito refere-se à interação emtre idade, gênero e abuso $(\mathrm{F}(2,72)=5.72 ; \mathrm{p}<0,05)$. Resultados post hoc indicam que idade tem um efeito sobre o enfrentamento em sua relação com o abuso emocional $(\mathrm{F}(2,72)$ 4.46; $\mathrm{p}<0,05)$.

\section{Impacto do abuso}

Foram computadas porcentagens para conhecer o impacto do abuso para idade e gênero.
As Tabelas 3 mostram as porcentagen para o impacto do abuso.

As porcentagens indicam que um número máximo de crianças declarou que o abuso leva à depressão e a sentimentos suicidas, e menor número indicou que eles não serão capazes de confiar em adultos por causa dos abusos que sofreram. Isto foi evidente em todos a três tipos de abuso. Por exemplo, 25\% das crianças declararam que, no abuso físico, Ramu abusará de drogas, enquanto apenas $12.5 \%$ das crianças declararam o mesmo para a condição de abuso emocional. Para o abuso sexual, 35\% disseram que Ramu vai se tornar um abusador e um criminoso, enquanto somente $20 \%$ e $17.5 \%$ das crianças observaram o mesmo para o abuso emocional e físico, respectivamente.

Quando comparando o impacto do abuso nos gêneros, pode ser visto que 22,5\% das meninas estavam sob a impressão que o abuso causará

Tabela 2a: Resultado médio quanto às capacidades de enfrentamento

\begin{tabular}{lcccccc}
\hline & \multicolumn{2}{c}{ Física } & \multicolumn{2}{c}{ Emocional } & \multicolumn{2}{c}{ Sexual } \\
& meninos & meninas & meninos & meninas & meninos & meninas \\
\hline Crianças mais jovens (5-9 anos) & 4.2 & 6.2 & 0.5 & 0.5 & 5.2 & 5.2 \\
Crianças mais velhas (10 -14 anos) & 4.6 & 7.6 & 6.4 & 7.8 & 5.2 & 6.0 \\
\hline
\end{tabular}

Tabela 2b: Desvio padrão para capacidade de enfentamento.

\begin{tabular}{lcccccc}
\hline & \multicolumn{2}{c}{ Física } & \multicolumn{2}{c}{ Emocional } & \multicolumn{2}{c}{ Sexual } \\
& meninos & meninas & meninos & meninas & meninos & meninas \\
\hline Crianças mais jovens (5- 9 anos) & 4.40 & 7.65 & 3.46 & 4.82 & 4.44 & 7.39 \\
Crianças mais velhas (10 -14 anos) & 3.44 & 7.09 & 4.08 & 7.41 & 3.54 & 6.23 \\
\hline
\end{tabular}

Tabela 3a: Porcentagem de respostas quanto ao impacto de abuso físico.

\begin{tabular}{lcccrr}
\hline Grau do impacto & $\mathbf{1}$ & $\mathbf{2}$ & $\mathbf{3}$ & \multicolumn{1}{c}{$\mathbf{4}$} & \multicolumn{1}{c}{$\mathbf{5}$} \\
\hline Crianças + jovens & 17.5 & 15.0 & 2.5 & 7.5 & 7.5 \\
Crianças + velhas & 17.5 & 10.0 & 5.0 & 7.5 & 10.0 \\
Total & 35.0 & 25.0 & 7.5 & 15.0 & 17.5 \\
\hline
\end{tabular}

Tabela 3b: Porcentagem de respostas quanto ao impacto de abuso emocional.

\begin{tabular}{lcrccc}
\hline Grau do impacto & $\mathbf{1}$ & \multicolumn{1}{c}{$\mathbf{2}$} & $\mathbf{3}$ & $\mathbf{4}$ & $\mathbf{5}$ \\
\hline Crianças + joven & 22.5 & 10.0 & 7.5 & - & 10 \\
Crianças + velhas & 25.0 & 2.5 & 2.5 & 10 & 10 \\
Total & 47.5 & 12.5 & 10 & 10 & 20 \\
\hline
\end{tabular}

Tabela 3c: Porcentagem de respostas quanto ao impacto de abuso sexual.

\begin{tabular}{lcrrrr}
\hline Grau do impacto & $\mathbf{1}$ & \multicolumn{1}{c}{$\mathbf{2}$} & $\mathbf{3}$ & \multicolumn{1}{c}{$\mathbf{4}$} & \multicolumn{1}{c}{$\mathbf{5}$} \\
\hline Crianças + jovens & 10.0 & 7.5 & 5.0 & 5.0 & 22.5 \\
Crianças + velhas & 15.0 & 2.5 & 2.5 & 17.5 & 12.5 \\
Total & 25.0 & 10.0 & 7.0 & 22.5 & 35.0 \\
\hline
\end{tabular}

depressão e sentimentos suicidas, enquanto somente $13 \%$ dos meninos sentiam o mesmo. Mais meninos sentiram ( $14.1 \%$ ) que o impacto levará ao abuso de drogas, comparado a somente $1.67 \%$ das meninas.

\section{ANALISE DA NARRATIVA}

Das 40 crianças que responderam ao método qualitativo de coleta de dados, somente 16 narrativas puderam ser obtidas. Foi muito difícil extrair a essência de cada estória e atribuir um rótulo a cada uma delas de acordo com o seu conteúdo. As transcrições das narrativas foram analisadas estruturalmente de modo a mostrar como foi atribuído o rótulo e o que foi compreendido através de uma frase particular está inserida entre parênteses ao lado das declarações da criança. O modo pelo qual a criança conta a estaria, seus gostos verbais e não-verbais, as respostas do examinador e as suas indagações, foram igualmente gravadas. 

a seguir.

Algumas das narrativas são apresentadas

Pensamentos suicidas: Sumi, 12 anos

"Era uma vez havia uma menina chamada Malini. Sua mãe morreu quando ela era um bebê depois de algum tempo seu pai trouxe uma madrasta. Depois da morte da mãe de Malini, Malini estava vivendo com as suas tias que judiavam dela fisicamente e emocionalmente, e faziam ela fazer todo o serviço de casa. A madrasta não gostava de Malini porque ela era escura, feia e estúpida" (indica sentimentos de desvalia). - Como a menina sabia que ela era escura e feia?

- Porgue a madrasta falava isto para ela e também porque ela não conseguia fazer nada direito (Suas tias estavam constantemente ralhando com ela e dizendo a ela que ela não podia fazer nada direito).

- Como ?

- Como cozinhar, lavar roupas etc...., e um dia ela quebrou a tigela de arroz e a madrasta ralhou com ela e queimou sua mão. Assim, a menina pensou: quero morrer, porque eu não posso ir à escola ou brincar como as outras crianças. Aí ela bebeu inseticida e morreu (idéias suicidas).

- As pessoas morrem quando tomam inseticida?

- Humm.... A tia vizinha morreu assim. Ela bebeu uma garrafa bem pequena e morreu antes que pudessem levá-la ao hospital. (Sumi pode estar pensando que a morte é melhor que a vida, desde que a vida está repleta de abusos).

A narrativa de Flor de Maçã: menina, 6 anos "Meu nome é Flor de Maçã. Eu vendo coisinhas para ajudar minha mãe ... Eu vou à escola. Estou no I ${ }^{\circ}$ grau (sua mãe é a única a ganhar o ganha-pão pois seu pai é um viciado). Algumas vezes, minha mãe vai à praia para arrumar dinheiro ... O dinheiro que eu ganho vendendo coisinha, eu dou para minha mãe e minha mãe compra mais coisinhas e nos dá para vender.... E, algumas vezes, as pessoas param os carros para nos dar dinheiro, pacotes de arroz... "

Assassinato das filhas do viciado

"Era uma vez numa calçada estavam a mãe, o pai, duas irmãs mais velhas e um irmãozinho. O pai era muito mau... e era um viciado. Um dia, o pai bateu em Maneka (filha) na sua cabeça com um grande pau quadrado e ela morreu ... e o pai lutou com a mãe.... pegou a irmã mais velha (9 anos) $e$ fugiu. Ele a matou e pôs seu corpo em uma panela com água e ferveu ... então uma raposa veio e pediu carne ... o pai disse não .. eu não vou dar ... E ele matou a raposa. Então o policial veio ... pegou o pai... colocou ele na cadeia. Então eles (polícia) bateram nele com um grande pau quadrado e o mataram." (Uma capacidade de enfrentamento?)

Flor de Maçã parece ter estado odiando o seu pai que é um viciado, embora nem ela nem sua mãe admitissem que o pai abusa das crianças. "Se eu matar meus inimigos, eu viverei".

\section{Ódio e agressão: Aru, 6 anos, menino}

"Uma vez havia um menino de rua, ele estava sempre muito zangado. Ele costumava destruir tudo - casas, brinquedos - todas as coisas ... Você sabe - (sentimentos de raiva) Então, o policial veio, pegou ele e pôs ele na prisão. De novo, ele começou a destruir as coisas (sentimentos de raiva). Então, o policial pôs ele na prisão de novo. Mas desta vez elefugiu”. - Então, o que aconteceu no final? - Bem... (parecendo confuso) mesmo no fnal ele estava muito zangado.

\section{Capacidades de enfrentamento \\ Nima: 10 anos}

Uma vez havia uma criança de rua na calçada. O policial levou ela embora enquanto a sua mãe foi ao municipal (latrina). Quando a mãe veio na delegacia procurar o menino, o policial se recusou a dar ele para a sua mãe, julgaram ele e mandaram ele para um reformatório ... e as pessoas de lá eram muito más ... Irritavam ele, importunavam ele e faziam ele levantar muito cedo e não deixavam os meninos menores ver televisão. E um dia o menino falou para si próprio que era demais. Assim, um dia ele levantou bem cedo de manhã e fugiu do reformatório com outros três meninos. Ele encontrou sua mãe e a mãe contou para o pai do menino que o menino tinha voltado. Seu pai levou ele para a sua cidade e depois disto a criança ficou muito feliz e foi para a escola.

\section{enfrentamento).}

(Resultados positivos da capacidade de

Talvez Nima queira ser como o menino na estória e cair fora do círculo vicioso do abuso.

\section{Impacto do abuso sexual...vício...? \\ Shan: 11 anos, menino}

"Era uma vez havia um pequeno menino de rua. Seu pai era um viciado e sua mãe costumava trabalhar de empregada para ganhar dinheiro. Ninguém gostava dele porque ele era teimoso. Mesmo seus pais, eles não compravam brinquedos para ele nem davam comida para ele, mas costumavam dar comida e roupas para as suas irmãs. Algumas vezes seu pai costumava roubar o seu dinheiro para comprar pó (drogas) .... Assim ele fugiu de casa e ficou na calçada, ali ele encontrou alguns meninos mais velhos, eles gostavam muito dele. Eles disseram: fique conosco, nós vamos dar brinquedos, doces e roupas para você. Eles deram chocolate para ele e um relógio brilhante, mas à noite eles costumavam fazer coisas feias com ele". (abuso sexual). sas...?

- Assim, o menino gostava daquelas coi-

- Não.... (longo silêncio) .... Mas, como os meninos eram mais bondosos com ele do que 
seus pais, ele pensava: eu vou ficar com esses meninos. (apego ao abusador). - O que acontece no fim?

- Ouando o menino cresceu? quando o menino cresceu, ele começou a usar pó ... e ele ficou muito doente e morreu.

O pai de Shan é um viciado e sua mãe trabalha como doméstica. Seu pai não trabalha e usa todos os tostões para comprar droga. Shan sofreu abuso sexual por um grupo de meninos mais velhos, mas ele diz que não se comunica mais com aqueles meninos. Sua quantidade de agressão foi excepcionalmente alta na condição de abuso sexual: escolheu o quadro que ilustra que ele gostaria de matar o violentador sexual, se ele fosse Ramu.

\section{DISCUSSÃO}

Em geral, os resultados indicaram que as crianças mais jovens demonstraram uma maior agressão do que as mais velhas, mostrando, como em pesquisas anteriores, que ambas - as formas de agressão e o modo como ela é expressa -, mudam com a idade. GOODENOUGH (1981) pediu às mães que elas mantivessem registros dos ataques de raiva de seus filhos. Viu que a agressão física era gradualmente substituída no decorrer dos anos da pré-escola. EIARTUP (1974) encontrou que a agressão instrumental declinava no período de 4 a 7 anos, enquanto os estouros orientados à pessoa hostil aumentavam. Para PARKE \& SLABY (1993), o rápido desenvolvimento da linguagem contribui para esta mudança, embora esta seja tambérn devida às reações fortemente negativas de crianças e adultos a empurrões, socos e mordidas. Os níveis mais baixos de agressão das crianças mais velhas podiam ser também devidos ao seu domínio maior quanto às manifestações das regras de conduta social assim como por serem mais capazes de esconder suas emoções. SARRANI (1999) observou que crianças de 7, 9 e 11 anos tinham controles variados sobre a manifestação das regras. Em uma sessão inicial, as crianças eram recompensadas com presentes atraentes, tais como uma barra de doce ou 50 centavos. Na sessão seguinte, quando elas esperavam um bom presente, ganhavam um brinquedo de bebê. As crianças de 7 anos, particularmente os meninos, foram incapazes de mascarar seu desapontamento e deixavam transparecer suas reações negativas. As crianças mais velhas, particularmente as meninas, foram mais capazes de esconder seu desapontamento e reafirmar as regras esperadas, pretendendo estar tudo ótimo.

Os meninos, em conjunto, foram mais agressivos do que as meninas, sugerindo estereó- tipos de gênero na percepção dos abusos. Numa revisão clássica de mais de 15.000 estudos (MACCOBY \& JACKLIN, 1974), comparando os gêneros masculino e feminino, concluíam que apenas quatro estereótipos de gênero usuais eram razoavelmente precisos, quais sejam, a capacidade verbal em favor de meninas e as capacidades espaciais e matemáticas e de agressão em favor dos meninos. Estudos subseqüentes mostraram que disparidades entre meninos e meninas eram bastante pequenas. De acordo com DEAUX (1981), o gênero não responde por mais do que $5 \%$ das diferenças individuais entre crianças. Igualmente, a vulnerabilidade das meninas pode tê-las feito selecionar ações menos agressivas do que aquelas dos meninos no presente estudo.

As crianças mais velhas, e mais freqüentemente as meninas, são mais capazes de enfrentar os abusos que sofreram e pensar em estratégias superiores de enfrentamento, quando comparadas com os meninos. PANICKER \& DESAI (1993) encontraram que as meninas de rua possuem surpreendentes capacidades de enfrentamento, embora elas recebam mais maus tratos e sejam mais exploradas do que os meninos de rua. A maioria delas estava cuidando da casa para a sua família, ganhando a vida e suportando a exploração dos homens da família.

As crianças estavam conscientes do impacto do abuso e da sua escolha dos quadros. Todas as crianças pensavam que Ramu iria ser afetado de algum modo como resultado do abuso que sofreu. As meninas, principalmente, indicaram idéias suicidas e uma incapacidade de mostrar emoção, enquanto os meninos escolheram o uso de drogas. Isto sugere que o impacto psicológico do abuso pode ser diferente em meninos e menmas, embora eles estejam expostos a situações similares de ameaça nas ruas.

Além disso, as narrativas das crianças retrataram seu sentimento de desvalia, tristeza raiva, depressão e idéias suicidas, através dos personagens que elas inventaram. Por exemplo, Sumi que estava sofrendo abuso de sua madrasta tanto fisicarnente quanto emocionalmente, disse que a menininha na estória tomou inseticida e morreu porque ela era escura e feia e ninguém a amava.

Outro impacto comum ao abuso, que apareceu nas narrativas das crianças, foi o sentimento de ódio, vingança e raiva. "Sempre que o policial batia nele, ele costumava atirar no policial e matá-lo”, disse Kuma, um menino de 6 anos, contando sobre um menino de rua que se tornou um gangster devido ao abuso fisico que sofreu.

De todos os abusos, o abuso sexual pareceu ser o pior no que se refere à criança que o sofreu. Todas as crianças expressaram o máximo 
de agressão quanto ao abuso sexual, seguido do abuso físico e do emocional. As crianças, no seu todo, manifestaram uma força menor quanto à capacidade de enfrentar o abuso sexual. Os psicólogos clínicos sugerem que, a despeito de adaptarem-se durante o abuso sexual, com o passar do tempo, as vítimas se tornam desadaptadas. Além do mais, os estilos de enfrentamento desadaptados se tornam mais complexos, devido à implicação de conseqüências deletérias desenvolvidas na vida posterior da vítima. As reações mais freqüentemente documentadas da vítima de abuso sexual em criança são as respostas emocionais de culpa, medo, ansiedade, depressão (usualmente reprimida) e hostilidade (BROWNE \& FINKE, 1989). Além disso, relatos clínicos emergiram ligando experiências de abuso sexual em criança com uma ampla extensão de experiências na vida posterior, incluíndo desordens de personalidade, uso de drogas, desvio sexual e crime sexual agressivo entre vítimas masculinas.

Portanto, em geral, foi observado que o abuso e violência em crianças é um fenômeno complexo e desastroso. Em resumo, os achados deste estudo indicaram que o abuso experimentado pelas crianças ocasionou um impacto psicológico em suas vidas, embora não "quebrem o seu espírito” completamente, dado elas possuírem, em alguma medida, capacidades de enfrentamento.

Agradecimentos: Os autores agradecem a cooperação e a generosidade do Presidente e do Pessoal no Sarvodaya Kulangana Sansadaya pela pemmissão de trabalhar com as crianças no projeto das crianças de rua de Sarvodaya Nossos agradecimentos mais calorosos aos pequenas amigos do Centro.

\begin{abstract}
Serões children firam sri Lanka be^tween $\wedge$ the ages of 5 Ad I I years were assessed for $\wedge$ the psychological impac $\wedge$ t of violence and abuse, by testing for $\wedge$ the amount of perceived aggression, $\wedge$ their coping sãos amd impact of abuse. Results indica $\wedge$ te tha $\wedge$ t the youmger children displayed more aggression than the older children amd the boys were more aggressive than the girls. Aggression was foremos $\wedge t$ for sexual abuse. The older children s«med to be able to cope better and the grils on the whole were more skilled in copmg tham the boys. The psychological impac $\wedge t$ of abuse seemed $\wedge$ to be more severe $\mathrm{m}$ the forms of depression amd snicidal thoughts. Mamy children felt that the abnsed would become an abuser or a criminal. I his has reaching consequences $m$ a lesser imdustrialized country like sri $\wedge$ Lanka, $\wedge$ though $\wedge$ the in $\wedge$ fluence is mainly $\sim \mathrm{m}$ on $\wedge$ tcome of nrbam industriaíization.
\end{abstract}

Key words: street children: violence; abuse; impact; sri Larka

\section{REFERÊNCIAS BIBLIOGRÁFICAS}

ARIMPOOR, J. C. Street children of Madras. Ghaziabad, National Labour Institute,1992. (Child labour cell).

BROOTA, K. D. Experimental design in behavioural research. New Delhi, Wiley Eastern Press, 1989.

BROWNE, O.; FINKE, O. Street children: an urban phenomena. In: Selected papers in child exploitation and abuse. The report of the fourth Asian conference on child exploitation and abuse. Calcutta, India, 1989.

CATTANACH, A. Play therapy with abused children. In: KEDAR, N.D. \& VERNA, V. (Eds.). How and why children hate. A study of conscious and unconscious sources. London, Briddles Ltda. Guilford and Kings, Lynn, 1993.

DEAUX, D. Development of sex related to differences and gender roles. In: BERK, L. E. Child development. Massachussetts, Allyn and Bacon, 1981. p.519-523.
FANTUZRO et al.The family effects of abuse. In: SIEGELMAN, C.K. \& SHAFFER, D. R. (Eds.). Life span human development. Baltimore, Wadsworth Publ. Co., 1999.

GERBNER, G.; GROOS, L.; SIGNORIELLI, N.; MORGAN, M.; JACKSON, B. M. The demonstration of power: violenceprofile. No.10. Journal of Communication, 29 (3): 177-195, 1979.

GOODENOUGH, C. Development of sex, related differences and gender roles. In: BERK, L.E. Child development. Massachussetes, Allyn and Bacon, 1981. p.519-523.

HARTUP, W.W. Aggression in childhood. Developmental perspectives. American Psychologist, 29: 336-341, 1974.

HOLDER \& RITCHIE. The family effects of abuse (1991). In: SIGELMAN, C. K.; SHAFFER, D. R. (Eds.). Life span human development. California, Brooks Cole Publ. Co.,1995.

JAFFE et al. How and why children hate. In: KEDAR, N.D.; VERNA, V. (Eds.). How and why children hate. A study of conscious and 
unconscious sources. London, Briddles Ltda. Guilford and Kings,Lynn, 1993.

KEMPE, C.H.; SILVERMAN, B. F.; STEELE, P. W.; DROEGEMUELLER, P. W.; SILVER, H. $\mathrm{K}$. The battered child sydrome. Journal of American Medical Association, 181: 17-24, 1962.

MACCOBY, E. E.; JACKLIN, C. N. The psychology of sex differences. Stanford, C. A., Standford UniversityPress, 1974.

MARTIN, H. P.; BEEZLEY, R; CONWAY, E. S.; KEMPE, C. H. The development of abused children. Advances in paediatrics. Chicago Year Book, Medical Publishers,1974.

PANDA, L. E. A case study of street children in Bhuwaneswar. Bhuvaneswar, National Institute of habitat management, 1994.

PANICKER, R.; NANGIA, P. Working and street children in Dehli. Ghaziabad, National labour institute, 1992. (Child labourcell).
SARRANI, C. Self conceptions, personality and emotional expression. In: SIEGELMAN, C.K. \& SHAFFER, D.R. (Eds.). Life span human development. California, Wadsworth Publ. Co., 1999.

PARKE, R. D.; SLABY, R. G. The development of aggression. In: HETHERINGTON, E. M. (Ed.). Handbook of child psychology. Vol. 4: Socialization, personlaity and social development. $4^{\mathrm{a}}$ ed. NewYork, Wiley,1993.

SCHECHETER, S.; ROBERT, G.S. Child's rights to pretection. In: COORAY, T.C. Child s rights, the Sri Lankan experience. Colombo, Gaonasekara \& Kularatna/Open University Press, 1976.

RIESSMAN, C.K. (Eds.). Narrative analysis. Newbury Park/Ca, SagePublications, 1993.

UNICEF. A profile of Srilankan child in crisis and conflict. Colombo, UNICEF, 1990.

WINER, B. Statistical principles of experimental design. New York, Mcgraw-Hill,1971.

Recebido em 30/10/2000 Revisto em 01/11/2000 Aceitado em 10/11/2000 